\title{
Determination of ultra-trace Pt, Pd and Rh in seawater using an off- line pre-concentration method and inductively coupled plasma mass spectrometry
}

\author{
Kai Liu ${ }^{\text {a, b }}$, Xuelu Gao ${ }^{\text {a, b, * }}{ }^{\text {, Li Li }}{ }^{c}$, Chen-Tung Arthur Chen ${ }^{\mathrm{d}}$, Qianguo Xing ${ }^{\text {a }}$ \\ ${ }^{a}$ CAS Key Laboratory of Coastal Environmental Processes and Ecological Remediation, Yantai Institute of Coastal Zone Research, Chinese Academy of \\ Sciences, Yantai, 264003, China \\ ${ }^{\mathrm{b}}$ University of Chinese Academy of Sciences, Beijing, 100049, China \\ c First Institute of Oceanography, State Oceanic Administration, Qingdao, Shandong, 266601, China \\ ${ }^{\mathrm{d}}$ Department of Oceanography, National Sun Yat-sen University, Kaohsiung, 80424, Taiwan
}

\section{H I G H L I G H T S}

- An off-line pre-concentration method for Pt, Pd and Rh in seawater was developed.

- The method had low system blanks and could quantitative recovery Pt, Pd and Rh.

- The method is easy to operate and the enrichment factor could reach to 200-fold.

- This method successfully tested the actual samples and obtained excellent results.

\section{A R T I C L E I N F O}

\section{Article history:}

Received 21 November 2017

Received in revised form

15 August 2018

Accepted 19 August 2018

Available online 20 August 2018

Handling Editor: Petra Petra Krystek

\section{Keywords:}

Platinum group elements

Seawater

ICP-MS

Pre-concentration

Chelating resin

\begin{abstract}
A B S T R A C T
A method was modified for the preconcentration of platinum (Pt), palladium (Pd) and rhodium ( $\mathrm{Rh}$ ) from seawater by a solid phase extraction using a commercially available resin Nobias-chelate PA $1^{\circledR}$. All the determination was conducted using inductively coupled plasma mass spectrometry (ICP-MS) which had a low detection limit for Pt, Pd and Rh, about 16.53, 16.41 and $26.88 \mathrm{pg} \mathrm{L}^{-1}$, respectively. It was found that the adsorption performance of the resin was closely related to the matrix, ligands and $\mathrm{pH}$ of the samples. Significant difference in recovery was found in various samples: seawater $\approx$ artificial seawater $>$ ultrapure deionized water. This method had low method blank in the range of $5.51-8.89 \mathrm{pg} \mathrm{L}^{-1}$ and high enrichment factor of up to $180-200$. The recoveries of Pt and Pd were $93 \pm 4.2 \%$ in the spiked real seawater. However, the recovery of Rh on the resin was below $70 \%$ but stable in the range of $65-68 \%$. It indicated that the Rh recovery seemed to be reproducible and higher volumes of seawater must be processed in order to obtain the lower limit of quantification and excellent recovery.
\end{abstract}

๑) 2018 Elsevier Ltd. All rights reserved.

\section{Introduction}

Platinum group elements (PGEs; including Pt, Pd, Rh, Os, Ir and $\mathrm{Ru})$ are trace elements with the content less than $1 \mu \mathrm{g} \mathrm{kg}^{-1}$ in the crust (Reith et al., 2014). However, these elements are widely used in modern industry because of their excellent characteristics such as antioxidant, catalytic activity, and corrosion resistance

\footnotetext{
* Corresponding author. CAS Key Laboratory of Coastal Environmental Processes and Ecological Remediation, Yantai Institute of Coastal Zone Research, Chinese Academy of Sciences, Yantai, 264003, China.

E-mail address: xlgao@yic.ac.cn (X. Gao).
}

(Wiseman and Zereini, 2009; Pawlak et al., 2014). Hence, an enormous amount of PGEs would be released into the environment with anthropogenic activities, especially the application of automobile catalytic system (Palacios et al., 2000; Ek et al., 2004; Wang et al., 2007; Ruchter and Sures, 2015). Current evidence has demonstrated their potential risks to human health and ecology (Kielhorn et al., 2002; Ravindra et al., 2004; Ducoulombier-Crépineau et al., 2007). For instance, the element Pt could get into the cells through the human skin and block some special biochemical reactions (Gebel et al., 1997; Schmid et al., 2007). Moreover, Pt, Pd and $\mathrm{Rh}$ could accumulate significantly in plants, eggs and some biological species (Turner et al., 2007; Bonanno, 2011; Almécija et al., 
2016). Furthermore, the solubility of PGEs could be enhanced with the presence of common compounds in the environment and their ions would mobilize and transform easily (Leopold et al., 2008; Reith and Cornelis, 2017). Therefore, it is necessary to monitor PGEs in various environment matrixes to investigate their bioavailability, biogeochemical behavior, and toxicity (Calvo Fornieles et al., 2016). In the past decades, researchers focused on the concentration level of PGEs in urban road dusts, organisms, sediments, and rivers (Turner et al., 2007; Bonanno, 2011; Cobelo-García et al., 2011; Suzuki et al., 2014; Almécija et al., 2016; Mashio et al., 2016). Nevertheless, the geochemical behavior of these elements has been known little in the marine environment, even in the coastal areas that are widely and profoundly influenced by human activities and river input. The limiting factors are the low concentration of PGEs and the coexisting elements in seawater (Machado et al., 2017) which could interfere in the detection of PGEs by reducing the analytical sensitivity of the instruments.

In response to the low value and complicated environment matrices, voltammetry techniques (Van den Berg and Jacinto, 1988; Cobelo-García et al., 2014) and pre-concentration approaches (Suzuki et al., 2014; Calvo Fornieles et al., 2016; Fischer et al., 2018) have been developed for the determination of PGEs in water samples at ultra-trace concentrations. Among these analytical methods, solid-phase extraction is considered as a preferable preconcentration procedure because it is reproducible, faster, cleaner, and requires smaller volumes of solvent and sample (Mladenova et al., 2012). Moreover, chelate resin extraction coupled with ICPMS or ICP-OES has been proven to be a powerful tool for an accurate multi-element analysis over a wide range of concentrations in seawater (Biller and Bruland, 2012; López Guerrero et al., 2016, 2017). For those, many synthesized or commercially available chelate resins have been used to extract PGEs from different matrixes, but a limited number of them are applied in PGEs analyses in seawater (Biller and Bruland, 2012; Hatje et al., 2014; Suzuki et al., 2014; López Guerrero et al., 2016, 2017). Calvo Fornieles et al. (2016) used an anion exchange chelating resin [silica gel functionalized with 1,5-bis (di-2-pyridyl) methylene thiocarbohydrazide] to simultaneously separate Pt, Pd and Ir from seawater and on-line determine their concentrations with ICP-OES. The method obtained an excellent recovery of Pt, Pd and Ir, about 94.5-105.8\%. Furthermore, Bio-Rad $A G^{\circledR} 1-\mathrm{X} 8$ as a commercially available anion exchange resin has been used to extract Pt in seawater at ultra-trace concentration (Suzuki et al., 2014; Mashio et al., 2016) but its application in the enrichment of Pd and Rh is limited (Bertine et al., 1996). Fischer et al. (2018) proposed a method for the preconcentration of $\mathrm{Ag}$ and $\mathrm{Pt}$ in seawater with the strong anion exchange resin Dowex ${ }^{\circledR} 1 \mathrm{X} 8$ and successfully applied this method to the detection of actual and reference samples. Hence, it is meaningful and promising to test the availability of a chelating resin that is commercially available and could simultaneously extract Pt, Pd and $\mathrm{Rh}$ in seawater. Nobias-chelate ${ }^{\circledR}$ PA1 seems to have this potential because of its strong affinity with a wide variety of trace metals by two functional groups: ethylenediaminetriacetic acid (EDTriA) and IDA (Sohrin et al., 2008). Moreover, this resin has been applied to the extraction of ultra-trace rare-earth elements from seawater simultaneously and expressed strong matrix tolerance (Persson et al., 2011; Takata et al., 2011; Hatje et al., 2014). Finally, it is a commercially available resin with stable property.

Therefore, an off-line method for simultaneous extraction of Pt, Pd and Rh in seawater by Nobias-chelate PA $1{ }^{\circledR}$ resin was proposed in present research. This method was modified and improved based on some former studies (Sohrin et al., 2008; Biller and Bruland, 2012; Lagerström et al., 2013; Hatje et al., 2014). The operation could be simply controlled and less contaminated, and allows for the loading of multiple samples simultaneously. We applied this method to extract Pt, Pd and Rh that are considered as the main PGEs pollutants in seawater and determine real coastal surface seawater in the North Yellow Sea. Unfortunately, due to the lack of $\mathrm{Pt}, \mathrm{Pd} \mathrm{Rh}$ references in our research, the recoveries of these elements were only conducted in spiked standard reference solutions (natural seawater).

\section{Experiment}

\subsection{Reagents}

The reagents mentioned in this research were trace metal grade (TMG) and supplied by Fisher Scientific. In order to avoid contamination and reduce the reagent blanks, concentrated nitric acid and concentrated hydrochloric acid were subjected by distillation of those TMG reagents in a sub-boiling distillation apparatus (DST-1000, Savillex ${ }^{\mathrm{TM}}$ ). The ammonium acetate $\left(\mathrm{NH}_{4} \mathrm{Ac}\right)$ buffer solution used to adjust the $\mathrm{pH}$ of the sample was produced by acetic acid (HAc) and $\mathrm{NH}_{4} \mathrm{OH}$. The Nobias-chelate $\mathrm{PA} 1^{\circledR}$ resin used in this research was manufactured by Hitachi High-Technologies with an average particulate diameter of $\sim 60 \mu \mathrm{m}$. The low-density polyethylene (LDPE) bottles (Nalgene ${ }^{\mathrm{TM}}$, Thermo Fisher Scientific Inc.) used for the storage of buffer solutions, seawater samples, standards and elution reagents were prepared following a strict acid cleaning process, and the ultra-pure deionized water $(\mathrm{QW})$ ( $>18 \mathrm{M} \Omega-\mathrm{cm}$ ) used in this study was produced by a Milli-Q (MQ) system. The reagent bottles were soaked with $10 \% \mathrm{HCl}$ for $\sim 24 \mathrm{~h}$ and then stored in $10 \% \mathrm{HNO}_{3}$ for another $24 \mathrm{~h}$ and then washed $3-5$ times with QW. The sample bottles $(50 \mathrm{~mL}, \mathrm{BD}$ FALCONTM $)$ and elution bottles ( $15 \mathrm{~mL}$, BD FALCON ${ }^{\mathrm{TM}}$ ) were cleaned by being filled with $3 \mathrm{M} \mathrm{HNO}_{3}$ and heated overnight in an ultrasonic cleaner, and then this operation was repeated in $3 \mathrm{M} \mathrm{HCl}$. All the experimental wares were dried in a Class 100 clean bench. The mixed stock solution of $1000 \mathrm{mg} \mathrm{L}^{-1} \mathrm{Rh}$, Pt and Pd in $2 \mathrm{M} \mathrm{HCl}$ was supplied by General Research Institute for Nonferrous Metals. The experimental operations were conducted in the HEPA filtered workbenches (Class 100) in a trace-metal clean laboratory (Class $100,22-25^{\circ} \mathrm{C}$ ) in the First Institute of Oceanography, State Oceanic Administration of China.

\subsection{Instrument and analysis}

In this study, the samples were measured using an inductively coupled plasma-mass spectrometer (ICP-MS, Element 2, Thermo Fisher Scientific Inc.) fitted with an Apex HF micro-nebulizer system (Elemental Scientific Inc.), and an internal standard (indium, $1 \mu \mathrm{g} \mathrm{L}^{-1}$ ) was spiked in every sample. The instrument was optimized by pumping a $1 \mu \mathrm{g} \mathrm{L}^{-1}$ tune solution ( $\mathrm{Li}, \mathrm{Ce}, \mathrm{Ba}$, In and $\mathrm{U}$ ) to monitor the oxide formation $(\mathrm{BaO} / \mathrm{Ba}<3 \%)$ and the sensitivity of In $\left(1 \mu \mathrm{g} \mathrm{L}^{-1}\right)$ was about $4,000,000 \mathrm{cps}$. Considering individual isotopic abundance, the data of the target elements were collected by measuring the most abundance mass of ${ }^{104} \mathrm{Pt},{ }^{105} \mathrm{Pt},{ }^{105} \mathrm{Pd},{ }^{106} \mathrm{Pd}$, ${ }^{108} \mathrm{Pd}$ and ${ }^{103} \mathrm{Rh}$ in low resolution with a mass resolving power of $300(\mathrm{~m} / \Delta \mathrm{m}$ at $5 \%$ peak height). The potential interference on Pt and $\mathrm{Rh}$ was assessed based on the data of ${ }^{178} \mathrm{Hf}$ and ${ }^{64} \mathrm{Zn}$ (Simitchiev et al., 2008; Fischer et al., 2018). The isobaric interference on Pd was corrected by monitoring ${ }^{200} \mathrm{Hg}$ and ${ }^{111} \mathrm{Cd}$, and the data of ${ }^{108} \mathrm{Pd}$ and ${ }^{65} \mathrm{Cu},{ }^{68} \mathrm{Zn},{ }^{85} \mathrm{Sr},{ }^{89} \mathrm{Y}$ and ${ }^{95} \mathrm{Mo}$ was used to monitor the potential polyatomic interference. As a quality control, a standard solution containing $0.1 \mu \mathrm{g} \mathrm{L}^{-1}$ of Pt, Pd and $\mathrm{Rh}$ in $1 \mathrm{~N} \mathrm{HNO}_{3}$ was run on the ICP-MS after the analysis of every 12 samples. The instrument blank was estimated by running $1 \mathrm{~N} \mathrm{HNO}_{3}$ acid after a run of per 12 samples during the detection to correct the instrumental baseline drift. The analytical parameters of the method are shown in Table 1. 
Table 1

Analysis parameter of the extraction method. Detection limit (LOD) and quantification limit (LOQ) are the results of the two individual channels in the extraction system.

\begin{tabular}{llll}
\hline & Pt & Pd & Rh \\
\hline Enrichment factor & $180-200$ & $180-200$ & $180-200$ \\
LQD $\left(\mathrm{pg} \mathrm{L}^{-1}\right)$ & $16.5 \pm 0.7$ & $16.4 \pm 0.4$ & $26.7 \pm 0.9$ \\
LOQ $\left(\mathrm{pg} \mathrm{L}^{-1}\right)$ & $55.1 \pm 2.3$ & $54.7 \pm 1.4$ & $89.6 \pm 3.1$ \\
\hline
\end{tabular}

\subsection{Sample collection}

Samples used in this study were surface seawater (2-3 m deep) collected on two sampling trips. One trip was in May 2015, and the other one was in March 2016. The sampling stations are shown in Fig. 1. The seawater sample used as the spiked standards was collected from station B23 in the North Yellow Sea in May 2015 and acidified to $\mathrm{pH} \sim 2$ with concentrated $\mathrm{HNO}_{3}$. In March 2016, the samples were collected from 5 stations, namely 3, 9, 15, S7 and S8, which were used for the test on actual samples. The sampling followed a strict trace-metal cleaning procedure that was modified based on Li et al. (2015). The sampling system consisted of a portable peristaltic pump (Cole-Parmer Inc.) equipped with precleaned C-flex ${ }^{\circledR}$ tubing (Cole-Parmer Inc.), and the intakes and connections were Teflon material. Seawater samples were filtered in-line through a $0.2 \mu \mathrm{m}$ capsule Opticap ${ }^{\circledR}$ polyethersulfone filter (Millipore Inc.), collected in a pre-cleaned $1 \mathrm{~L}$ LDPE bottle (Nalgene $^{\mathrm{TM}}$, Thermo Fisher Scientific Inc.), and then acidified to a $\mathrm{pH} \sim 2$ with concentrated $\mathrm{HNO}_{3}$. The samples were stored frozen $\left(-20^{\circ} \mathrm{C}\right)$ and approximately $1 \mathrm{~mL}$ concentrated $\mathrm{HCl}$ was added to each of them before the extraction experiment to transform the complex of PGEs to $\mathrm{M}(\mathrm{Cl})_{\mathrm{n}}^{\mathrm{m}-\mathrm{n}}(\mathrm{m}=2-5 ; \mathrm{n}=4-6)$ (Colombo et al., 2008; Gerber et al., 2010).

The cleaning procedure was performed according to $\mathrm{Li}$ et al. (2015). The C-flex ${ }^{\circledR}$ tubes were first washed with Decon $90^{\circledR}$ and soaked with $10 \% \mathrm{HCl}$ for $24 \mathrm{~h}$, and then stored in $2 \% \mathrm{HNO}_{3}$ for further use. The sample bottles were also pre-cleaned using Decon $90^{\circledR}$, but then washed with $30 \% \mathrm{HNO}_{3}, 30 \% \mathrm{HCl}$ and QW respectively, followed the details in Li et al. (2015). Each bottle was double bagged in polyethylene bags, and stored (at $20-25^{\circ} \mathrm{C}$ ) for further use. The Millipore ${ }^{\circledR}$ filters were pre-cleaned with $2 \% \mathrm{HNO}_{3}$ and then rinsed with QW before use.

\subsection{Pre-concentration process}

The pre-concentration system used in this study was adjusted and developed based on a reported method (Biller and Bruland,
2012; Hatje et al., 2014). We did not change the specific structure of the extraction system, but only adjusted the volumes of samples and elutions. The schematic diagram of the extraction process is shown in Fig. 2. The extraction system was connected by $1 / 16^{\prime \prime}$ O.D. $\times 0.04^{\prime \prime}$ I.D. perfluoroalkoxy (PFA) Teflon tube (IDEX) and 4way PEEK flow switching valves (IDEX), which could simultaneously operate 2 samples. A 6-channel peristaltic pump (LongerPump $^{\circledR}$, Longer Precision Pump Co. Ltd) was used to load the samples and rinse the system at a flow rate of about $0.5 \mathrm{~mL} \mathrm{~min}{ }^{-1}$. The elution was operated by pressurizing the system using high purity nitrogen at a pressure of 3-5 psi. The extraction chamber used in the system was a $2 \mathrm{~cm}$ long micro column (non-metal frits, Global FIA) with an inner volume approximately $27 \mu \mathrm{L}$, and this type of column has been widely used in flow-based devices for preconcentrating metal elements from seawater samples (Biller and Bruland, 2012; Hatje et al., 2014). The Nobias-chelate PA1 ${ }^{\circledR}$ resin, pre-activated in $1 \mathrm{M} \mathrm{HCl}$, was loaded into the column using a pipette $\left(10-100 \mu \mathrm{L}\right.$; Eppendorf Reference $\left.{ }^{\circledR}\right)$.

The enrichment devices, including injection tubes, valves and columns, were pre-cleaned with $10 \% \mathrm{HNO}_{3}$. It is important to note that the PFA tube wall should be continuously flushed with $10 \%$ $\mathrm{HNO}_{3}$ and QW, and the resin in the column should be soaked in $0.1 \mathrm{~N} \mathrm{HNO}_{3}(>24 \mathrm{~h})$. Prior to the loading of the samples, the $\mathrm{HNO}_{3}$ in the extraction system was emptied and four-way valves were adjusted to connect the $\mathrm{H}-\mathrm{C} 1-\mathrm{W}$ line. About $8-10 \mathrm{~mL} 1 \mathrm{~N} \mathrm{HNO}_{3}$ was loaded to flush the tube and activate the resin. Then, S1-C1-W was connected, and the resin was washed with $\sim 3 \mathrm{~mL}$ of $0.05 \mathrm{M} \mathrm{NH}_{4} \mathrm{Ac}$ buffer. This operation was to ensure the resin was suitable to adsorb the Pt, Pd and $\mathrm{Rh}$ ions in the sample by changing the exchange sites of the resin from the $\mathrm{H}^{+}$to the $\mathrm{NH}_{4}^{+}$form (Hatje et al., 2014). Then, $\sim 200 \mathrm{~mL}$ of pre-weighed sample (adjust $\mathrm{pH}$ to $7.0 \pm 0.2$ by $3.7 \mathrm{M}$ of $\mathrm{NH}_{4}$ Ac with the $\mathrm{pH} 9.54 \pm 0.2$ ) was passed through the extraction unit at the flow rate of $0.5 \mathrm{~mL} \mathrm{~min}^{-1}$. After the loading of the sample, the four-way valve was adjusted to connect the S1-C1-W line, and $\sim 3 \mathrm{~mL} 0.05 \mathrm{M} \mathrm{NH}_{4} \mathrm{Ac}$ was pumped through the system. In this step, interfering ions, such as $\mathrm{Cl}$ and $\mathrm{Na}^{+}$, which attached to the resin's surface, were removed. Finally, Pt, Pd and Rh which retained on the resin were eluted with $1 \mathrm{~N} \mathrm{HNO}_{3}$ using the line $\mathrm{N}$ $\mathrm{C} 1-\mathrm{T}$. The rinsing process was driven by high purity nitrogen at a pressure of 3-5 psi and about $1 \mathrm{~mL}$ of elution was collected. After elution, $\sim 3 \mathrm{~mL}$ of $1 \mathrm{~N} \mathrm{HNO}_{3}$ was passed through the column for the testing of the effects of the eluent amount on the leaching efficiency and the elimination of the carryover between the samples. The high recycling rate of the Nobias-chelate PA $1{ }^{\circledR}$ resin has been demonstrated, and hundreds of samples could be extracted by one column (Biller and Bruland, 2012; Hatje et al., 2014). It was worth noting

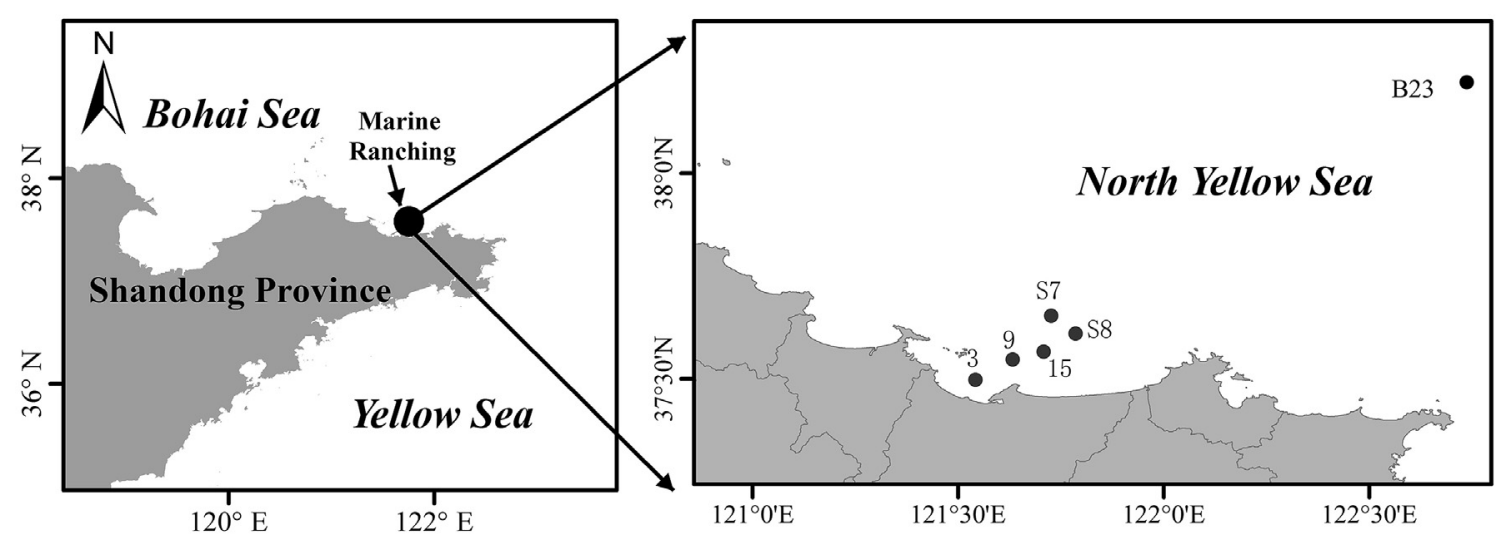

Fig. 1. Study area and sampling sites in the coastal water of the North Yellow Sea. The black dots in the right panel indicate the sampling sites. 


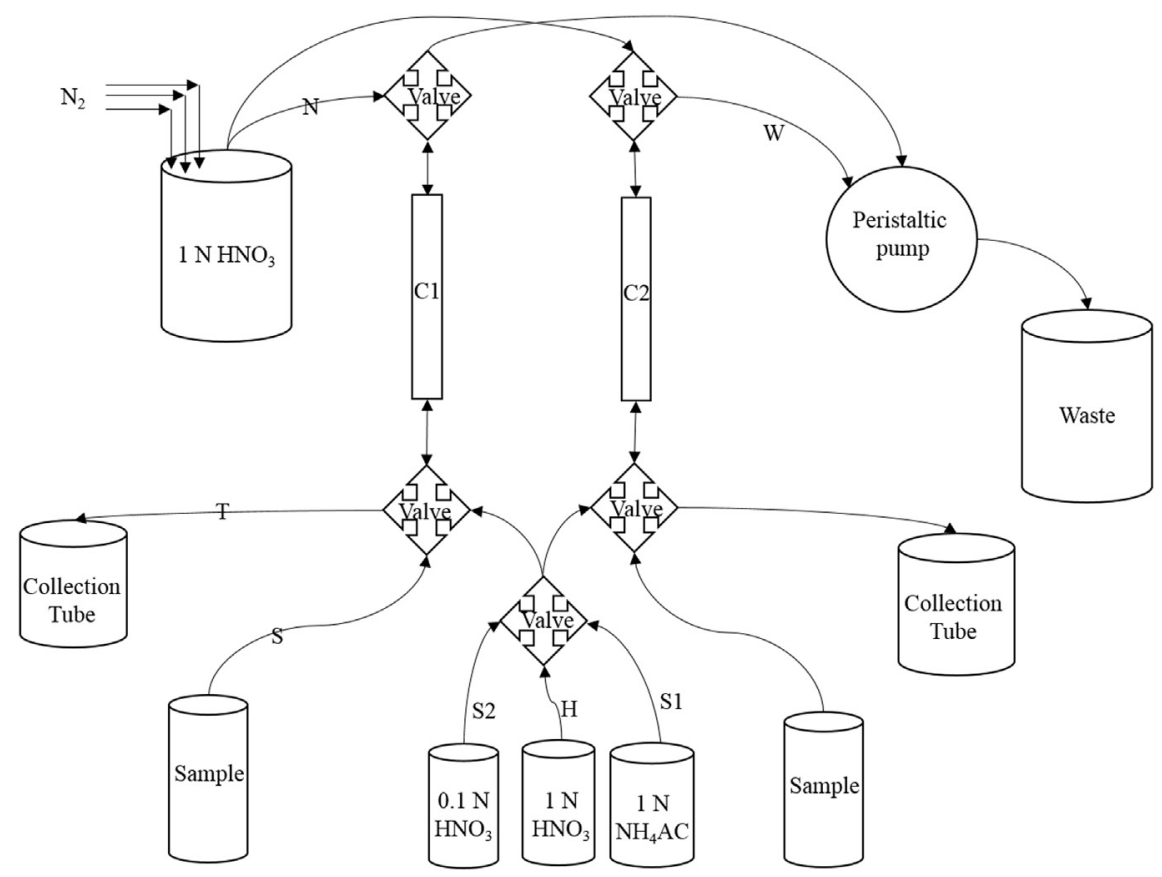

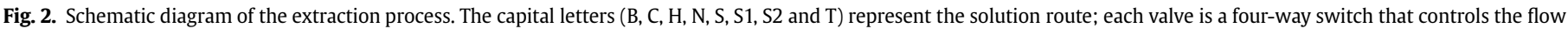
of solutions. This system allows for loading 2 samples simultaneously.

that the quality of the collection vials should be weighed before and after elution to obtain the mass of the elution sample. Method blanks including the contribution of the rinse, the elution acid, the PA1 resin and the instrument were produced by loading $200 \mathrm{~mL}$ of sample pre-cleaned by PA1 resin five times in each extraction channel (Biller and Bruland, 2012; Hatje et al., 2014; Fischer et al., 2018).

Considering the strong complexation of $\mathrm{Pt}$, Pd and $\mathrm{Rh}$ with organic matter (Turner et al., 2008; Cobelo-García, 2013), we investigated the interference of organic matter in seawater on the pre-concentration. The sample was irradiated at $220 \mathrm{~V} / 60 \mathrm{~Hz}$ for 200 min (Kuma et al., 1996; Achterberg et al., 2001) in the UVOCleaner ${ }^{\circledR}$ irradiated apparatus (Model NO. 5144AX-220, Jelight Inc.). The reaction chamber was a $200 \mathrm{~mL}$ PFA tank which was covered with a quartz cover embedded in a lid. The background DOC concentration of the UV digested sample was detected by a total organic carbon analyzer ( $\mathrm{TOC}-\mathrm{V}_{\mathrm{CPH}}$, Shimadu) and was less than $0.01 \mathrm{mg} \mathrm{L}^{-1}$.

\subsection{Data calculation and correction}

The concentrations of PGEs in the samples were calculated based on the following quantitative equations. The (1) and (2) were the basic formula. Equation (1) is used to calculate the enrichment factor $(F)$ : the ratio of sample mass to eluent mass. Consider the breakthrough of the resin, the uncontrollable error caused by sample matrix and experiment operation, and the ultra-level of PGEs, a correction factor $f_{R}$ was added to the equation (2) to obtain the equation ( 3$)$. $f_{R}$ is the average recovery $(n=3)$ of the Pt, Pd and $\mathrm{Rh}$ in the spiked seawater $\left(10 \mathrm{ng} \mathrm{L}^{-1}\right)$ after a run of every 5 samples. If $f_{R}$ is greater than $90 \%$, it is believed that the enrichment system is operating normally. While $75 \%<\mathrm{f}_{\mathrm{R}}<89 \%$, it is believed some errors may have occurred in the extraction, but the data is still credible after the correction by $f_{R}$. Once $f_{R}$ is less than $75 \%$, the recovery of Pt, $\mathrm{Pd}$ and $\mathrm{Rh}$ in the spiked seawater will be conducted for another three times. If the average recovery $(n=6)$ is still less than $75 \%$, the system is considered to have problems or the extraction exceeds the load capacity of the resin, and the column must be replaced. The average recovery is calculated after a run of every 15 samples to one column. By the correction of the equations, it is easy to judge the stability of the experiment and more reliable results could be obtained.

$\mathrm{F}=\frac{M_{S}}{M_{E}}$

$C_{S}=\frac{C_{E}}{F}$

$f_{R}=\frac{R}{3}$

$C_{S C}=\frac{C_{E}}{f_{R} \times F}$

F: the enrichment factor of the extraction; $M_{s}$ : the mass of the sample; $M_{E}$ : the mass of the elution; $C_{S}$ : the concentration of PGEs in sample; $C_{E}$ : the concentration of PGEs in eluent; R: the recovery of PGEs in spiked seawater $\left(10 \mathrm{ng} \mathrm{L}^{-1}\right)$ every 5 samples; $f_{R}$ : the average recovery of standard addition sample of the PGEs-free seawater, $\mathrm{n}=3 ; C_{S C}$ : the concentration of PGEs in sample after correction.

\subsection{Lab-prepared artificial reference materials}

Two kinds of standard addition seawater samples, represented by AW and YW, were prepared in our research owing to the lack of commercially available reference materials in our lab.

The AW was prepared by standard addition to artificial seawater sample in which Pt, Pd and Rh were free. The artificial seawater was prepared according to the standard method D1141-98 (Reapproved 2013; American Society for Testing and Materials, ASTM). In order to get the quantitative and accurate spikes, 1,10 and $100 \mu \mathrm{g} \mathrm{L}^{-1}$ of the mixed stock $2 \% \mathrm{HNO}_{3}$ solutions of $\mathrm{Pt}$, $\mathrm{Pd}$ and $\mathrm{Rh}$ were prepared 
with serial dilution from $1000 \mathrm{mg} \mathrm{L}^{-1}$ stock solution of these three elements and the precise concentrations were determined by ICPMS. Then, the artificial standard seawater was spiked with different mixed stock solutions, and the final work concentrations of the standard samples were $0.1,0.5,1$ and $10 \mathrm{ng} \mathrm{L}^{-1}$, respectively.

The YW was prepared according to the method proposed by Hatje et al. (2014). The seawater used for the preparation of the YW was collected from the North Yellow Sea in May 2015 (station B23 in Fig. 1). Prior to the preparation, the seawater was UV-digested and then cleaned with Nobias-chelate $\mathrm{PA}{ }^{\circledR}$ in $\mathrm{pH}=7.0 \pm 0.2$ to ensure that no Pt, Pd and Rh were present. Afterwards, the seawater was acidified to $\mathrm{pH}=2.0 \pm 0.2$ by adding $\sim 1 \mathrm{~mL}$ concentrated $\mathrm{HCl}$, and then stored in $1 \mathrm{~L}$ LDPE bottles. Similar to the preparation of AW reference materials, four standard spiked seawater samples were prepared. The recoveries of Pt, Pd and Rh in the lab-prepared artificial reference materials could not only help test the reliability of the extraction but also eliminate the interference caused by the difference in sample matrix. Furthermore, the use of the seawater standards for calibration, with quantitative recovery by the resin, eliminated the need to perform isotope dilution to account for variations in recovery of the resin (Biller and Bruland, 2012).

\section{Results and discussion}

\subsection{Blanks, detection limits, and interferences}

The method blank of extraction mainly involved two aspects. One was the reagent blank, which was caused by the reagents used in the pre-concentration such as $\mathrm{NH}_{4} \mathrm{OH}$ buffer solution, $\mathrm{HNO}_{3}$ and $\mathrm{HCl}$. The other blank was the system blank, caused by the extraction system of the column, piping, other manifold and the instrument blank. The detection limits (LOD) for the PGEs were calculated based on $3 \sigma$ (three times of the standard deviation of the blanks, $\mathrm{n}=11$ ), and the quantification limits (LOQ) were ten times of the $\sigma$ (Table 1). The enrichment factor (F) of the extraction calculated by the ratio between the mass of sample and elution was 180-200.

The accurate detection of Pt, Pd and Rh using ICP-MS is often disturbed by physical interference, isobaric interferences, polyatomic interferences and matrix effects. The physical interference induced by instrument could be eliminated by the inner standard In. The matrix interferences were not taken into account because the PA1 resin does not adsorb the microelement e.g. $\mathrm{Na}^{+}, \mathrm{Mg}^{2+}, \mathrm{K}^{+}$, $\mathrm{Ca}^{2+}$ in seawater (Sohrin et al., 2008). Therefore, the interferences which hamper the accurate measurements of Pt, Pd and Rh are mainly from the isobaric elements and polyatomic interferences. The interferences on Pt are mainly from the element ${ }^{179} \mathrm{Hf}$, e.g. the polyatomic $\mathrm{HfO}^{+}$has interference on all Pt isotopes (Fischer et al., 2018). However, there was no significant $\mathrm{HfO}^{+}$formation $(<1 \%)$ under the instrument condition used in this study and the Hf ions in seawater was not adsorbed by the PA1 resin under the standard addition experiment. Hence, the data of Pt did not need to be corrected because the interference contribution of Hf was little. For Rh, the interference was controlled by monitored the signals of ${ }^{40} \mathrm{Ar}^{63} \mathrm{Cu}^{+},{ }^{87} \mathrm{Sr}^{16} \mathrm{O}^{+},{ }^{87} \mathrm{Rb}^{16} \mathrm{O}^{+}$, and ${ }^{206} \mathrm{~Pb}^{2+}$. For $\mathrm{Pd}$, a significant interference of ${ }^{68} \mathrm{Zn}$ and ${ }^{108} \mathrm{Cd}$ on ${ }^{108} \mathrm{Pd}$, and ${ }^{106} \mathrm{Cd}$ and ${ }^{65} \mathrm{Cu}$ on ${ }^{105} \mathrm{Pd}$ was observed. These interferences derive from the polyatomic interferences of ${ }^{68} \mathrm{Zn}^{40} \mathrm{Ar}$ and ${ }^{65} \mathrm{Cu}^{40} \mathrm{Ar}$ and isobaric interferences of ${ }^{108} \mathrm{Cd}$ and ${ }^{106} \mathrm{Cd}$. In order to obtain the accurate data, the following correction formula were used to eliminate the interferences.

$I_{P d}=I_{P d, t}-I_{Z n A r}-I_{C d}-I_{C u A r}$

$I_{R h}=I_{R h, t}-I_{C u A r}-I_{S r O}-I_{R b O}-I_{P d}$

In which, $I_{P d}$ and $I_{R h}$ are the correction concentrations of Pd and
$\mathrm{Rh} ; I_{P d, t}$ and $I_{R h, t}$ are the total concentrations of Pd and Rh, isobaric interferences, and polyatomic interferences; $I_{Z n A r}, I_{C d}, I_{C u A r}, I_{S r O}, I_{R b O}$, $I_{P d}$ are the concentrations of isobaric and polyatomic interferences.

\section{2. $\mathrm{pH}$ conditions}

$\mathrm{pH}$ is an important factor that affects the adsorption efficiency of the resin to the target element (Kaur et al., 2007; Sun et al., 2012). Several researchers demonstrate that Nobias-chelate PA $1^{\circledR}$ resin exhibits an excellent adsorption capacity for many elements in a wide pH range 4-8 (Sohrin et al., 2008; Biller and Bruland, 2012). However, for Pt, Pd and Rh, the adsorption performance of PA1 resin exhibits a strong pH-dependence in QW (Sohrin et al., 2008). Therefore, the standard addition recoveries of Pt, Pd and $\mathrm{Rh}$ in the YW samples were conducted to obtain the optimum $\mathrm{pH}$ for the extraction method at a $\mathrm{pH}$ range 5.6-7.2. The recovery of each element was repeated 3 times with different $\mathrm{pH}$ in each. The various recoveries of $\mathrm{Pt}, \mathrm{Pd}$ and $\mathrm{Rh}$ with different $\mathrm{pH}$ in each channel of the extraction manifold are shown in Fig. 3. It could be found that these elements exhibited diverse responses to their adsorption on the Nobias-chelate PA $1{ }^{\circledR}$ resin in this range of $\mathrm{pH}$. Pt showed a high and stable recovery (85-95\%), and the recovery of $\mathrm{Pd}$ increased with the change of $\mathrm{pH}$ to alkaline direction. In the low pH range about 5.6-6.4, the recovery of Pd was only $45-65 \%$, and when the $\mathrm{pH} \approx 7$, the recovery could reach more than $90 \%$. The recovery of $\mathrm{Rh}$ was consistently below $70 \%$, and the values stabilized at approximately $65 \%$ at $\mathrm{pH} \approx 7$. In general, the highest recoveries of $\mathrm{Pt}, \mathrm{Pd}$ and $\mathrm{Rh}$ were obtained at $\mathrm{pH}=7.0 \pm 0.2$. Therefore, we chose this $\mathrm{pH}$ range as the optimum adsorption condition for the extraction method.

The factors controlling the adsorption capacity of the Nobiaschelate PA ${ }^{\circledR}$ resin to PGEs are functional groups EDTriA and IDA (Supplementary Material Fig. S1). These two functional groups capture the target elements by forming the stable complexes with the $-\mathrm{N}$ : and $-\mathrm{O}^{-}$(Supplementary Material Fig. S1). However, it is difficult for these groups to destroy the chemical bond that have similar polarity e.g. $\mathrm{OH}^{-}$. Hence, the EDTriA and IDA may prefer to capture the PGEs ions complexing with $\mathrm{Cl}^{-}$, which results in the recovery of Rh being lower than $\mathrm{Pt}$ and $\mathrm{Pd}$. The reason for this is that the complexes of Pt and Pd in seawater are mainly composed of $\left[\mathrm{PtCl}_{3} \mathrm{OH}^{2-}\right] /\left[\mathrm{PtCl}_{4}^{2-}\right]$ and $\left[\mathrm{PdCl}_{3} \mathrm{OH}^{2-}\right] /\left[\mathrm{PdCl}_{4}^{2-}\right]$ (Byrne and Yao, 2000; Colombo et al., 2008), while the complexes of Rh are dominated by $\mathrm{Rh}(\mathrm{OH})_{\mathrm{n}}^{3-\mathrm{n}}$ (Gerber et al., 2010). Moreover, those complexes could transform significantly with the change of the $\mathrm{pH}$. The complexes of PGE-OH increase with the $\mathrm{pH}$ of the seawater changing to the alkaline direction, and the complexes of PGE-Cl increase with the $\mathrm{pH}$ shifting to the acidic direction (Byrne and Yao, 2000; Colombo et al., 2008; Gerber et al., 2010). In the $\mathrm{pH}$ range selected in this study (5.6-7.2), the complexes of Pt and Rh are stable, while the complexes of Pd could undergo a dramatic change from Pd-Cl to Pd$\mathrm{Cl}-\mathrm{OH}$ (Byrne and Yao, 2000; Colombo et al., 2008). This may be the reason that the recovery of $\mathrm{Pd}$ showed a fluctuation with $\mathrm{pH}$.

\subsection{Effects of the sample matrix}

The sample matrix significantly determines the complex forms of Pt, Pd and Rh in seawater (Byrne and Yao, 2000; Colombo et al., 2008; Gerber et al., 2010). Previously, researchers thought that the complexes of PGEs in seawater were dominated by inorganic ligands (Colombo et al., 2008). However, recent studies demonstrated that PGEs could form stable complexes with the dissolved organic matter (DOM) (Turner et al., 2008; Cobelo-García, 2013). Moreover, researchers showed concerns that some organically bound elements (e.g. Cu and La) could lead to the low recovery of the Nobias-chelate PA $1^{\circledR}$ resin (Biller and Bruland, 2012; Hatje et al., 

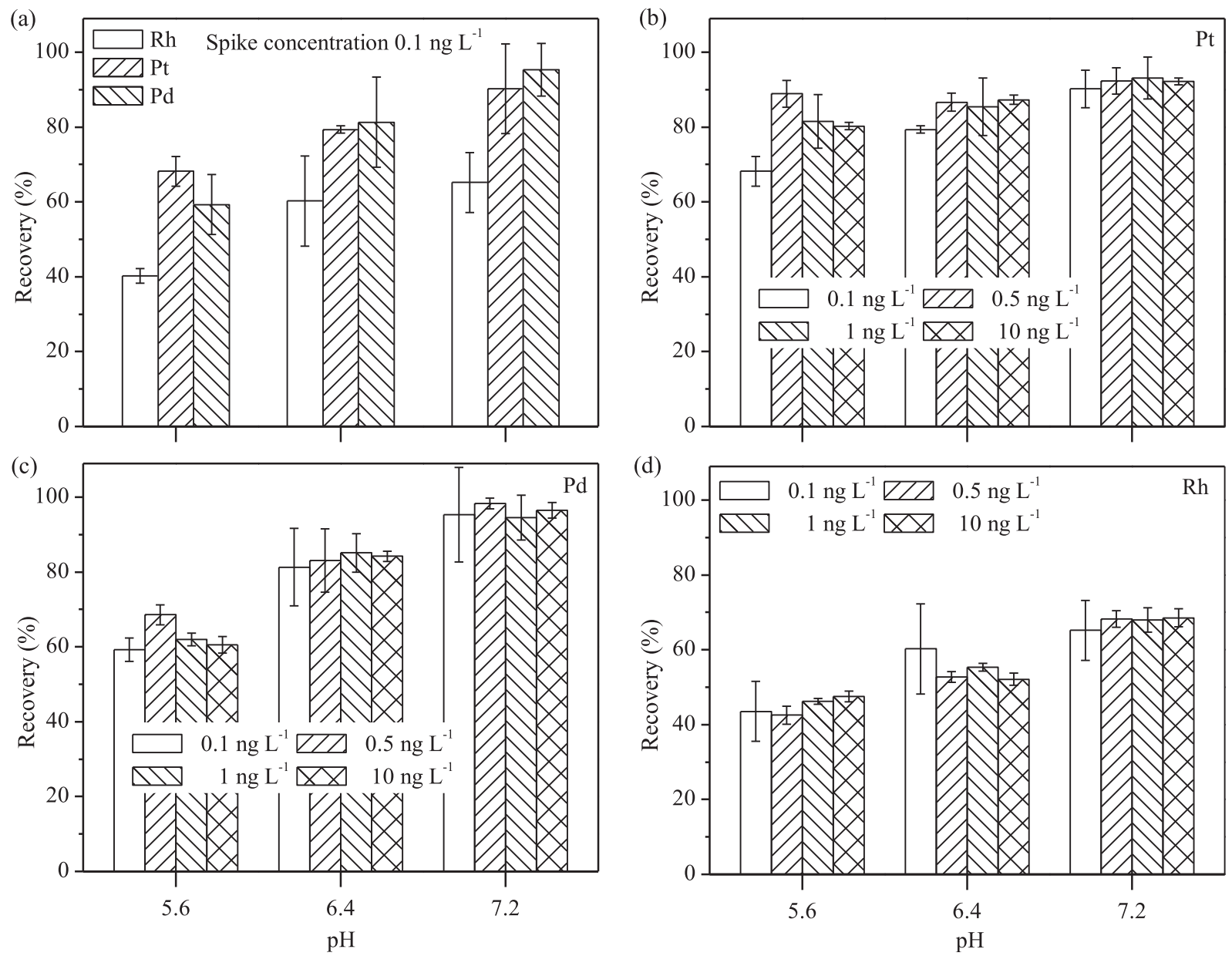

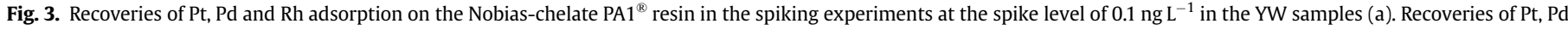
and $\mathrm{Rh}$ in different $\mathrm{pH}$ and spike concentrations in the YW samples are shown in (b), (c) and (d), respectively.

2014). Therefore, an ultraviolet irradiation pretreatment process to remove the DOM in the YW sample was conducted to investigate the interference of organic complexation on the extraction. This method is adequate to destroy metal-binding organic ligands for a range of trace metals (Milne et al., 2010; Biller and Bruland, 2012). In addition, controlled extraction experiments on Pt, Pd and $\mathrm{Rh}$ in artificial seawater without being UV-digested and PGEs-free

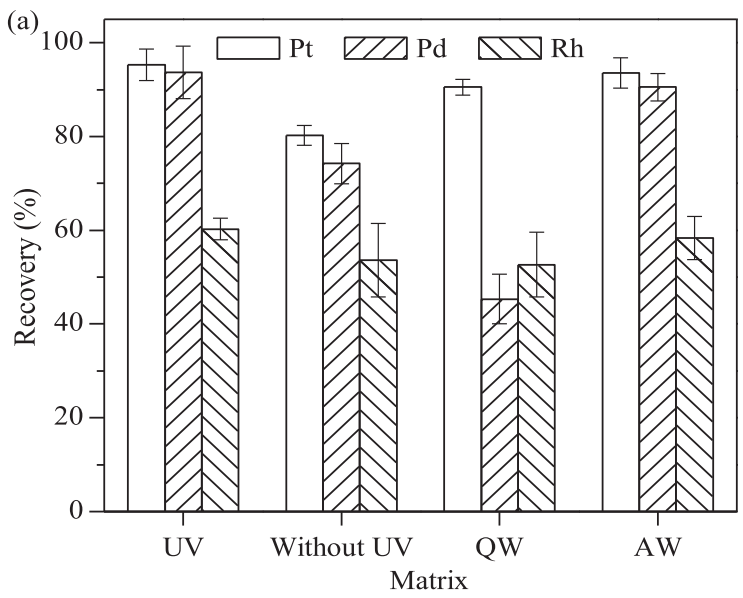

seawater were also carried out simultaneously. Fig. 4a shows the recoveries of Pt, Pd and Rh adsorption on Nobias-chelate PA ${ }^{\circledR}$ resin under different pretreatment conditions. Various responses in recovery could be found for different elements and matrices, and the higher recovery was obtained in the experiments on the UVdigested samples. The recovery of the UV-treated samples was 117.6-137.9\% of the untreated samples. Furthermore, a similar

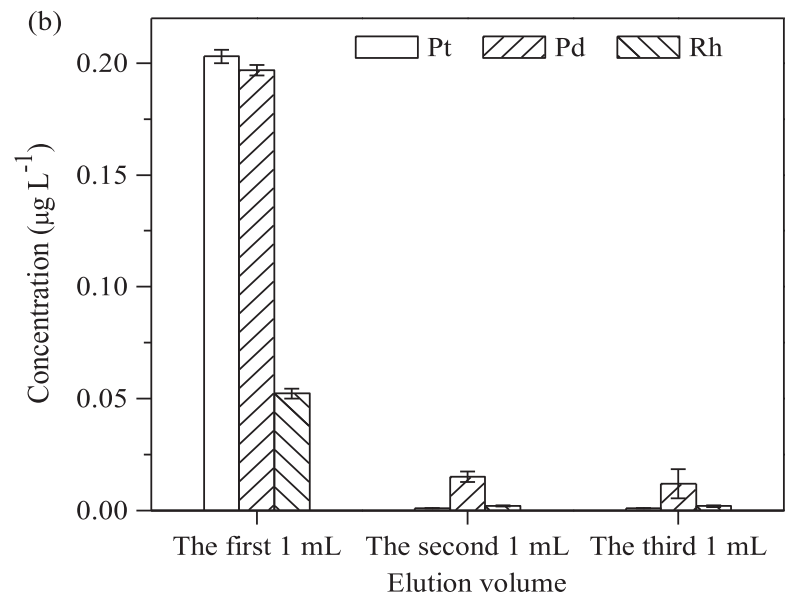

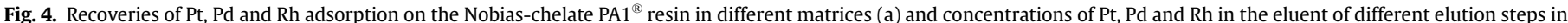

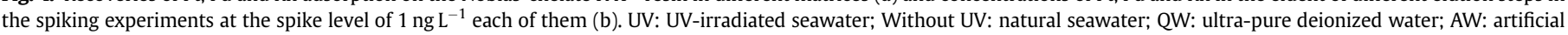
seawater. 
recovery of Pt, Pd and Rh in the UV-treated samples and the artificial seawater samples was obtained (Fig. 4a). This evidence indicated that the organic matter in seawater might hamper the adsorption of PGEs on the Nobias-chelate PA $1^{\circledR}$ resin.

Besides the aforementioned aspect, a reversal phenomenon was also found. The Nobias-chelate PA $1^{\circledR}$ resin is expected to have a better adsorption performance on PGEs in the $\mathrm{QW}$ than in the seawater, because the QW contains no interference substances. However, the recovery of Pd in the QW was lower than in the seawater in this study. This phenomenon may result from the transformation of Pd complexes in different matrices. In the $\mathrm{QW}$, the speciation of $\mathrm{Pd}$ is predominated by $\mathrm{Pd}-\mathrm{OH}$ complexes according to the thermodynamic experiments and calculations (Byrne and Yao, 2000; Colombo et al., 2008). But with the increase of the concentration of chloride ions in the water, the form of Pd complexes changes from $\mathrm{Pd}-\mathrm{OH}$ to $\mathrm{Pd}-\mathrm{OH}-\mathrm{Cl}$. As that was mentioned above in section 3.2, thermodynamically, the former form was more stable than the latter. Hence, the functional groups on the resin could not effectively extract Pd in the QW samples resulting in a decrease of recovery. The chemical species changes of $\mathrm{Pd}$ and $\mathrm{Rh}$ in different environmental matrices are shown in Supplementary Material Fig. S2.

\subsection{Effects of the sample and elution volume}

Due to the low concentration of PGEs in seawater, which is approximately $0.98 \mathrm{pmol} \mathrm{kg}^{-1}$ (Ojeda and Rojas, 2007), a higher enrichment factor is highly beneficial for achieving a greater efficiency of extraction. Hence, it is necessary to control the mass ratio of the sample volume to the elution volume. According to the existing experimental conditions, increasing the sample volume would significantly extend the loading time and reduce the efficiency of extraction. On the other hand, if the volume of sample is too small (e.g. $<100 \mathrm{~mL}$ ), it is hard to get enough eluent with the expected degree of enrichment for instrument. Therefore, in this study, 200 and $150 \mathrm{~mL}$ seawater samples were selected to investigate the effect of the volume. As a result, it was found that the recovery of the $200 \mathrm{~mL}$ sample ( 93\%) was higher than the $150 \mathrm{~mL}$ $(\sim 82 \%)$. Although the exact reason for this is unclear, the ultra-low concentration of PGEs in the samples would be a key factor. Insufficient sample volume and ultra-low concentration increased the determination difficulty of the instrument and resulted in errors. Hence, $200 \mathrm{~mL}$ was a proper sample volume for the extraction.

To increase the enrichment factor, it is more convenient to control the eluent volume than sample volume. In previous studies with the similar extraction system, two sample-eluent ratios about $100 \mathrm{~mL}$ sample to $1 \mathrm{~mL}$ eluent (Biller and Bruland, 2012) and $70 \mathrm{~mL}$ sample to $0.4 \mathrm{~mL}$ eluent (Hatje et al., 2014) were used. Hence, a total of $3 \mathrm{~mL}$ eluent, added with $1 \mathrm{~mL}$ each time for 3 times, was used to elute the elements considering the larger volume of the samples in this study. Fig. 4b shows the concentrations of Pt, Pd and Rh in different sequentially added eluents. It could be found that more than $95 \%$ of the elements adsorbing on the resin were eluted at the first $1 \mathrm{~mL}$ eluent. In contrast, less than 3\% of the elements were detected in the second and third $1 \mathrm{~mL}$. Therefore, $1 \mathrm{~mL}$ eluent was enough to remove the $\mathrm{Pt}, \mathrm{Pd}$ and $\mathrm{Rh}$ retained on the resin.

\subsection{Recovery}

The estimate of resin recovery was carried out by comparing the calibration slope of the seawater standard additions with the slope of $1 \mathrm{~N} \mathrm{HNO}_{3}$ standard for all metals, as that was described in Biller and Bruland (2012) and Hatje et al. (2014). In order to evaluate the interference caused by the difference among the extraction columns, the recoveries of Pt, Pd and Rh in every channel in the experiments on the YW samples at different $\mathrm{pH}$ values were tested, and the results are shown in Supplementary Material Table S1. It was found that the differences in the recoveries gained from different columns were little. The recoveries of Pd and Pt were 94.5-98.3\% and 93.3-98.3\%, respectively, and Rh had the lowest values about $65.2-68.5 \%$. These results were consistent with the discussion in sections 3.2 and 3.3. The data discrepancies among different elements might be caused by the chemical species of Pt, $\mathrm{Pd}$ and $\mathrm{Rh}$ in seawater, the stability of their complexes, and the polarity of the resin functional groups.

As discussed in section 3.2, the complexes of Rh in seawater might be dominated by $\mathrm{Rh}-\mathrm{OH}$ under the optimum $\mathrm{pH}$ condition in the extraction of this research (Colombo et al., 2008). Nevertheless, the functional groups adsorbing $\mathrm{Pt}, \mathrm{Pd}$ and $\mathrm{Rh}$ on the Nobiaschelate PA ${ }^{\circledR}$ resin are mainly composed of $\mathrm{N}$ atoms and $\mathrm{O}$ atoms (Supplementary Material Fig. S1), which have similar polarity with $\mathrm{OH}^{-}$. Hence, the adsorption ability of Rh ions on the Nobias-chelate $\mathrm{PA} 1{ }^{\circledR}$ resin in seawater is lower than that of Pt and Pd ions. The excellent recovery of Pd adsorption on PA1 resin might result from the change in chemical species of this element. In $\mathrm{QW}$, the complexes of Pd are mainly in the form of $\mathrm{Pd}-\mathrm{OH}$, which hindered the adsorption of the resin. However, with the increase of the concentration of chloride ions, the complexes of Pd changed from Pd$\mathrm{OH}$ to $\mathrm{Pd}-\mathrm{Cl}$ in seawater (Colombo et al., 2008). Hence, the recovery of Pd increased with the appearance of chemical bonds which could be destroyed more easily by the functional groups of PA1, but the complexes of Rh was still in Rh-OH form. For Pt, the chemical bonds of Pt-OH and Pt-Cl complex may be similar and weaker than Pd$\mathrm{OH}-\mathrm{Cl}$ and Rh-OH (Wood, 1991; Colombo et al., 2008; Bugarčić et al., 2015). Hence, the resin exhibited different adsorption capacity for Pt, Pd and $\mathrm{Rh}$ in seawater.

\subsection{Contrast with other methods}

Although the detection of platinum group elements in seawater is challenging, researchers have proposed some solutions for this work. In order to evaluate the advantages and disadvantages of our extraction method, we compared similar solid-liquid extraction methods adopted in the publications.

Calvo Fornieles et al. (2016) proposed a method of extracting Pt, Pd and Ir in standard addition seawater by their own lab-prepared resin DPTH-gel and had an excellent detection limit about 1.4, 0.5 and $0.6 \mu \mathrm{g} \mathrm{L}^{-1} \mathrm{Pt}$, Pd and $\mathrm{Ir}$, respectively. The eluent volume of their method was $18 \mathrm{~mL}$ and the enrichment factor was 6.3-6.7. This enrichment factor is insufficient for extracting the ultraconcentration of PGEs in natural seawater. However, this resin showed excellent selectivity to PGEs in seawater and may have appreciative application prospect. For our method, only $1 \mathrm{~mL}$ of eluent was needed to remove more than $95 \%$ of the elements retained on the resin, and the enrichment factor could reach 180-200. This factor could effectively enrich Pt, Pd and Rh from natural seawater. Suzuki et al. (2014) used a commercially available resin $A G^{\circledR} 1-X 8$ to extract Pt from seawater and achieved satisfactory results. The detection limit and process blank were very low, only 2.93 and $1.95 \mathrm{pg} \mathrm{L}^{-1}$, and the enrichment factor could reach about 600 -fold. However, the enrichment time of their method was about $24 \mathrm{~h}$ to one seawater sample, which may limit work efficiency in real application.

For our method, approximately $200 \mathrm{~mL}$ of sample was required, the extraction time of one sample was about $5 \mathrm{~h}$, and multi-samples (>4) could be conducted simultaneously. Moreover, the eluent only needed one simple collection step in our method. The analytical performance data of this and related methods reported in the literature are listed in Table 2. It could be found that previous 
Table 2

Analytical performance information in different research.

\begin{tabular}{|c|c|c|c|c|c|c|c|c|}
\hline \multirow[t]{2}{*}{ Sample } & \multirow[t]{2}{*}{ Instrument } & \multirow[t]{2}{*}{ Extraction agent } & \multirow[t]{2}{*}{ Loading time } & \multirow[t]{2}{*}{ Enrichment factor } & \multicolumn{3}{|c|}{ Detection limit $\left(\mathrm{pg} \mathrm{L}^{-1}\right)$} & \multirow[t]{2}{*}{ Reference } \\
\hline & & & & & Pt & Pd & $\mathrm{Rh}$ & \\
\hline Tokyo Bay water & ICP-MS & $\mathrm{AG}^{\circledR} 1 \mathrm{X}-8$ & $8 \mathrm{~h}$ & $\sim 600$ & 2.95 & $-{ }^{a}$ & - & Mashio et al. (2016) \\
\hline Ocean water & GFAA & $\mathrm{AG}^{(\mathbb{R})} 1 \mathrm{X}-8$ & $>20 \mathrm{~h}$ & 44.4 & 15 & - & - & Hodge et al. (1986) \\
\hline Ocean water & ICP-QMS & $\mathrm{AG}^{\circledR} 1 \mathrm{X}-8$ & $8 \mathrm{~h}$ & $\sim 600$ & 2.95 & - & - & Suzuki et al. (2014) \\
\hline Estuarine water & ID-ICP-MS & $\mathrm{AG}^{\circledR} 1 \mathrm{X}-8$ & $6-24 h$ & $200-250$ & 1.87 & - & - & Obata et al. (2006) \\
\hline Seawater & ICP-OES & DPTH-gel & $\sim 1 \mathrm{~h}$ & $6.7 ; 6.3$ & $0.5^{\mathrm{b}}$ & $0.6^{\mathrm{b}}$ & - & Calvo Fornieles et al. (2016) \\
\hline Seawater & ICP-SFMS & Dowex $^{\mathbb{B}} 1 \mathrm{X} 8$ & $\sim 1 \mathrm{~h}$ & 40 & 3.9 & - & - & Fischer et al. (2018) \\
\hline Coastal water & ICP-MS & Nobias-chelate PA $1^{\circledR}$ & $\sim 5 \mathrm{~h}$ & $180-200$ & 16.53 & 16.41 & 26.88 & This work \\
\hline
\end{tabular}

a “-” represents no relevant reference data.

b In $\mu \mathrm{g} \mathrm{L}^{-1}$.

Table 3

Concentration of Pt in different water samples. For the sake of comparison, the results in other literature were kept in line with the data of this study presenting in pmol kg-1.

\begin{tabular}{lll}
\hline Sample & Concentration of Pt $\left(\mathrm{pmol} \mathrm{kg}^{-1}\right)$ & Reference \\
\hline Pacific Ocean water & $0.19-1.13$ & Hodge et al. (1986); Suzuki et al. (2014) \\
Estuarine water & $4.88-30.7$ & Obata et al. (2006) \\
River water & $0.18-5.79$ & Soyol-Erdene and Huh (2012) \\
Tokyo Bay water & $0.27-7.74$ & Mashio et al. (2016) \\
Otsuchi Bay water & $0.60-14.2$ & Mashio et al. (2016) \\
Rain water & $0.13-0.62$ & Mashio et al. (2016) \\
Coastal water & $1.28-4.48$ & This study \\
\hline
\end{tabular}

methods have their own shortcomings, e.g. the longer loading time of sample, lower enrichment factor, and non-simultaneousoperation in other solid-phase extraction methods of PGEs in seawater (Hodge et al., 1986; Bertine et al., 1996; Mashio et al., 2016). In contrast, the off-line extraction method used in this study is easily controlled and the applicability is better than some on-line methods with ICP-MS. The on-line extraction method usually means longer working hours, which greatly affects instrument performance and increases operating costs. Therefore, the method used in this study was a low-cost way for simultaneous extraction of Pt, Pd and Rh in seawater.

\subsection{Application to actual seawater samples}

In this study, the method we built was used to investigate the concentrations of Pt, Pd and Rh in the surface seawater of 5 stations $(3,9,15$, S7 and S8 in Fig. 1) in the coastal area of the North Yellow Sea, and the data were compared with those reported in the literature. The concentrations of the three elements in the investigated coastal waters were low, with $1.31-4.59 \mathrm{pmol} \mathrm{kg}^{-1} \mathrm{Pt}$, $0.97-1.41 \mathrm{pmol} \mathrm{kg}^{-1} \mathrm{Pd}$ and $0.16-0.42 \mathrm{pmol} \mathrm{kg}^{-1} \mathrm{Rh}$ (the actual concentration of Rh may have been underestimated because of its lower recovery, and the detailed data are shown in the Supplementary Material Table S2). Table 3 shows the concentrations of Pt in different natural water samples (there is a lack of the data for dissolved Pd in literature and the data of dissolved Rh was only obtained in Ocean water). Compared with the data obtained from the oceanic environment (Pt: $0.23-0.24 \mathrm{pmol} \mathrm{kg}^{-1}$, Suzuki et al., 2014; Rh: $0.3-0.9 \mathrm{pmol} \mathrm{kg}^{-1}$, Bertine et al., 1996), these elements had obvious enrichment in coastal waters. Their accumulation in coastal waters may come from both natural and anthropogenic sources through various channels and is a result of the interaction of many complicated biogeochemical processes. It was reported that the farther away from the city the lower concentration of Pt in the river (Cobelo-García, 2013), which shows a clear anthropogenic impact. In contrast, research indicated that the concentration of Pt (1.27-4.58 pmol kg-1) in the Tokyo Bay was higher than that in the water from the surrounding rivers
(0.29-1.46 pmol kg-1) (Obata et al., 2006; Mashio et al., 2016), so other factors rather than riverine discharge should be responsible for this. However, there is a lack of the data of dissolved Pd and Rh in rivers and seas, so more research is needed in future.

\section{Conclusions}

In this study, an off-line method for simultaneous extraction of Pt, Pd and Rh using chelate resin PA1 from seawater was built and tested. This method is simple to operate, could enrich multiple samples simultaneously, and has low detection limits and blanks. Excellent recoveries for Pt and Pd were obtained with this enrichment method, about 92.2-98.3\% and 94.5-98.3\%, respectively. However, the recovery of Rh was low, only $65.2-68.5 \%$. Moreover, the use of lower volume of eluent allowed for this method achieving a high enrichment factor of about 200, which made the extraction of ultra-trace PGEs from seawater efficient. Due to the lack of commercially available reference materials in our lab, labprepared artificial standards were used in this research to validate the method. The detected values of Pt and Pd were consistent with the quantity spiked to the standards, but only two-thirds of Rh was recovered. This method has been successfully applied to the detection of Pt, Pd and $\mathrm{Rh}$ in actual seawater samples, and the data of Pt was consistent with the references. In summary, it is a feasible and promising method for the detection of dissolved platinum group elements in seawater.

\section{Acknowledgements}

We would like to thank all the group members for their constant field and laboratory assistance, helpful advice and in-depth discussion. This study was financially supported by the National Natural Science Foundation of China (41376083), the Aoshan Technology Innovation Program of the Qingdao National Laboratory for Marine Science and Technology (2016ASKJ02-4) and the Strategic Priority Research Program of the Chinese Academy of Sciences (XDA11020702, XDA11020305). 
Appendix A. Supplementary data

Supplementary data related to this article can be found at https://doi.org/10.1016/j.chemosphere.2018.08.098.

\section{References}

Achterberg, E.P., Braungardt, C.B., Sandford, R.C., Worsfold, P.J., 2001. UV digestion of seawater samples prior to the determination of copper using flow injection with chemiluminescence detection. Anal. Chim. Acta 440, 27-36.

Almécija, C., Cobelo-García, A., Santos-Echeandía, J., Caetano, M., 2016. Platinum in salt marsh sediments: behavior and plant uptake. Mar. Chem. 185, 91-103.

ASTM. (American Society for Testing and Materials), 2013. Standard Practice for the Preparation of Substitute Ocean Water. https://www.astm.org/Standards/D1141. html.

Bertine, K.K., Koide, M., Goldberg, E.D., 1996. Comparative marine chemistries of some trivalent metals bismuth, rhodium and rare earth elements. Mar. Chem. $53,89-100$.

Biller, D.V., Bruland, K.W., 2012. Analysis of Mn, Fe, Co, Ni, Cu, Zn, Cd, and Pb in seawater using the Nobias-chelate PA1 resin and magnetic sector inductively coupled plasma mass spectrometry (ICP-MS). Mar. Chem. 130-131, 12-20.

Bonanno, G., 2011. Trace element accumulation and distribution in the organs of Phragmites australis (common reed) and biomonitoring applications. Ecotoxicol. Environ. Saf. 74, 1057-1064.

Bugarčić, Ž.D., Bogojeski, J., van Eldik, R., 2015. Kinetics, mechanism and equilibrium studies on the substitution reactions of $\mathrm{Pd}(\mathrm{II})$ in reference to $\mathrm{Pt}(\mathrm{II})$ complexes with bio-molecules. Coord. Chem. Rev. 292, 91-106.

Byrne, R.H., Yao, W.S., 2000. Formation of palladium (II) hydroxychloride complexes and precipitates in sodium chloride solutions and seawater. Geochem. Cosmochim. Acta 64, 4153-4156.

Calvo Fornieles, A., García de Torres, A., Vereda Alonso, E., Cano Pavón, J.M., 2016. Simultaneous determination of traces of Pt, Pd, and Ir by SPE-ICP-OES. Test for chemical vapor generation. Microchem. J. 124, 82-89.

Cobelo-García, A., 2013. Kinetic effects on the interactions of Rh(III) with humic acids as determined using size-exclusion chromatography (SEC). Environ. Sci. Pollut. Res. 20, 2330-2339.

Cobelo-García, A., Neira, P., Mil-Homens, M., Caetano, M., 2011. Evaluation of the contamination of platinum in estuarine and coastal sediments (Tagus Estuary and Prodelta, Portugal). Mar. Pollut. Bull. 62, 646-650.

Cobelo-García, A., Santos-Echeanidía, J., López-Sánchez, D.E., Almécija, C. Omanović, D., 2014. Improving the voltammetric quantification of III-defined peaks using second derivative signal transformation: example of the determination of platinum in water and sediments. Anal. Chem. 86, 2308-2313.

Colombo, C., Oates, C.J., Monhemius, A.J., Plant, J.A., 2008. Complexation of platinum, palladium and rhodium with inorganic ligands in the environment. Geochem. Explor. Environ. Anal. 8, 91-101.

Ducoulombier-Crépineau, C., Feidt, C., Rychen, G., 2007. Platinum and Palladium transfer to milk, organs and tissues after a single oral administration to lactating goats. Chemosphere 68, 712-715.

Ek, K.H., Rauch, S., Morrison, G.M., Lindberg, P., 2004. Platinum group elements in raptor eggs, faeces, blood, liver and kidney. Sci. Total Environ. 334, 149-159.

Fischer, L., Smith, G., Hann, S., Bruland, K.W., 2018. Ultra-trace analysis of silver and platinum in seawater by icp-sfms after off-line matrix separation and preconcentration. Mar. Chem. 199, 44-52.

Gebel, T., Lantzsch, H., Plessow, K., Dunkelberg, H., 1997. Genotoxicity of platinum and palladium compounds in human and bacterial cells. Mutat. Res-Gen. Toxcol. Environ. 389, 183-190.

Gerber, W.J., Koch, K.R., Rohwer, H.E., Hosten, E.C., Geswindt, T.E., 2010. Separation and quantification of $\left[\mathrm{RhCl}_{n}\left(\mathrm{H}_{2} \mathrm{O}\right)_{6-\mathrm{n}}\right]^{3-\mathrm{n}}(\mathrm{n}=0-6)$ complexes, including stereoisomers, by means of ion-pair HPLC-ICP-MS. Talanta 82, 348-358.

Hatje, V., Bruland, K.W., Flegal, A.R., 2014. Determination of rare earth elements after pre-concentration using NOBIAS-chelate PA-1 resin: method development and application in the San Francisco Bay plume. Mar. Chem. 160, 34-41.

Hodge, V., Stallard, M., Koide, M., Goldberg, E.D., 1986. Determination of platinum and iridium in marine waters, sediments, and organisms. Anal. Chem. 58, 616-620.

Kaur, V., Aulakh, J.S., Malik, A.K., 2007. A new approach for simultaneous determination of $\mathrm{Co}(\mathrm{II}), \mathrm{Ni}(\mathrm{II}), \mathrm{Cu}(\mathrm{II})$ and $\mathrm{Pd}(\mathrm{II})$ using 2-thiophenaldehyde-3-thiosemicarbazone as reagent by solid phase microextraction high performance liquid chromatography. Anal. Chim. Acta 603, 44-50.

Kuma, K., Nishioka, J., Matsunaga, K., 1996. Controls on iron(III) hydroxide solubility in seawater: the influence of $\mathrm{pH}$ and natural organic chelators. Limnol. Oce anogr. 41, 396-407.

Kielhorn, J., Melber, C., Keller, D., Mangelsdorf, I., 2002. Palladium - a review of exposure and effects to human health. Int. J. Hyg Environ. Health 205, 417-432.

Lagerström, M.E., Field, M.P., Séguret, M., Fischer, L., Hann, S., Sherrell, R.M., 2013. Automated on-line flow-injection icp-ms determination of trace metals ( $\mathrm{Mn}, \mathrm{Fe}$ $\mathrm{Co}, \mathrm{Ni}, \mathrm{Cu}$ and $\mathrm{Zn}$ ) in open ocean seawater: application to the GEOTRACES program. Mar. Chem. 155, 71-80.

Leopold, K., Maier, M., Weber, S., Schuster, M., 2008. Long-term study of palladium in road tunnel dust and sewage sludge ash. Environ. Pollut. 156, 341-347.

Li, L., Liu, J.H., Wang, X.J., Shi, X.F., 2015. Dissolved trace metal distributions and Cu speciation in the southern Bohai Sea, China. Mar. Chem. 172, 34-35.
López Guerrero, M.M., Vereda Alonso, E., Cano Pavón, J.M., Siles Cordero, M.T., García de Torres, A., 2016. Simultaneous determination of chemical vapour generation forming elements ( $\mathrm{As}, \mathrm{Bi}, \mathrm{Sb}, \mathrm{Se}, \mathrm{Sn}, \mathrm{Cd}, \mathrm{Pt}, \mathrm{Pd}, \mathrm{Hg}$ ) and non-chemical vapour forming elements (Cu, Cr, Mn, Zn, Co) by ICP-OES. J. Anal. Atom. Spectrom. 31, 975-984.

López Guerrero, M.M., Alonso, Vereda, Cano Pavón, E., J. M, 2017. Simultaneous determination of traces of Pt, Pd, Os, Ir, Rh, Ag and Au metals by magnetic SPEICP-OES and in situ chemical vapour generation. J. Anal. Atom. Spectrom. 32, 2281-2291.

Machado, R.C., Amaral, C.D.B., Schiavo, D., Nóbrega, J.A., Nogueira, A.R.A., 2017. Complex samples and spectral interferences in ICP-MS: evaluation of tandem mass spectrometry for interference-free determination of cadmium, tin and platinum group elements. Microchem. J. 130, 271-275.

Mashio, A.S., Obata, H., Tazoe, H., Tsutsumi, M., Santos, A.F.I., Gamo, T., 2016. Dissolved platinum in rainwater, river water and seawater around Tokyo Bay and Otsuchi Bay in Japan. Estuar. Coast Shelf Sci. 180, 160-167.

Milne, A., Landing, W., Bizimis, M., Morton, P., 2010. Determination of Mn, Fe, Co, $\mathrm{Ni}, \mathrm{Cu}, \mathrm{Zn}, \mathrm{Cd}$ and $\mathrm{Pb}$ in seawater using high resolution magnetic sector inductively coupled mass spectrometry (HR-ICP-MS). Anal. Chim. Acta 665, 200-207.

Mladenova, E., Dakova, I., Karadjova, I., Karadjov, M., 2012. Column solid phase extraction and determination of ultra-trace Au, Pd and Pt in environmental and geological samples. Microchem. J. 101, 59-64.

Obata, H., Yoshida, T., Ogawa, H., 2006. Determination of picomolar levels of platinum in estuarine waters: a comparison of cathodic stripping voltammetry and isotope dilution-inductively coupled plasma mass spectrometry. Anal. Chim. Acta $580,32-38$

Ojeda, C.B., Rojas, F.S., 2007. Determination of rhodium: since the origins until today ICP-OES and ICP-MS. Talanta 71, 1-12.

Palacios, M.A., Gomez, M., Moldovan, M., Gomez, B., 2000. Assessment of environmental contamination risk by $\mathrm{Pt}, \mathrm{Rh}$ and $\mathrm{Pd}$ from automobile catalyst. Microchem. J. 67, 105-113.

Pawlak, J., Łodyga-Chruścińska, E., Chrustowicz, J., 2014. Fate of platinum metals in the environment. J. Trace Elem. Med. Biol. 28, 247-254.

Persson, P.O., Andersson, P.S., Zhang, J., Porcelli, D., 2011. Determination of Nd isotopes in water: a chemical separation technique for extracting $\mathrm{Nd}$ from seawater using a chelating resin. Anal. Chem. 83, 1336-1341.

Ravindra, K., Bencs, L., Van Grieken, R., 2004. Platinum group elements in the environment and their health risk. Sci. Total Environ. 318, 1-43.

Reith, F., Campbell, S.G., Ball, A.S., Pring, A., Southam, G., 2014. Platinum in Earth surface environments. Earth Sci. Rev. 131, 1-21.

Reith, F., Cornelis, G., 2017. Effect of soil properties on gold and platinum nanoparticle mobility. Chem. Geol. 466, 446-453.

Ruchter, N., Sures, B., 2015. Distribution of platinum and other traffic related metals in sediments and clams (Corbicula sp.). Water Res. 70, 313-324.

Schmid, M., Zimmermann, S., Krug, H.F., Sures, B., 2007. Influence of platinum, palladium and rhodium as compared with cadmium, nickel and chromium on cell viability and oxidative stress in human bronchial epithelial cells. Environ. Int. 33, 385-390.

Simitchiev, K., Stefanova, V., Kmetov, V., Andreev, G., Sanchez, A., Canals, A., 2008. Investigation of icp-ms spectral interferences in the determination of Rh, Pd and Pt in road dust: assessment of correction algorithms via uncertainty budget analysis and interference alleviation by preliminary acid leaching. Talanta 77, 889-896.

Sohrin, Y., Urushihara, S., Nakatsuka, S., Kono, T., Higo, E., Minami, T., Norisuye, K. Umetani, S., 2008. Multielemental determination of GEOTRACES key trace metals in seawater by ICP-MS after preconcentration using an ethylenediaminetriacetic acid chelating resin. Anal. Chem. 80, 6267-6273.

Soyol-Erdene, T.O., Huh, Y., 2012. Dissolved platinum in major rivers of East Asia: implications for the oceanic budget. Geochem. Geophy. Geosy. 13, 1-13.

Sun, P.P., Lee, J.Y., Lee, M.S., 2012. Separation of platinum(IV) and rhodium(III) from acidic chloride solution by ion exchange with anion resin. Hydrometallurgy 113-114, 200-204.

Suzuki, A., Obata, H., Okubo, A., Gamo, T., 2014. Precise determination of dissolved platinum in seawater of the Japan sea, sea of Okhotsk and western North Pacific ocean. Mar. Chem. 166, 114-121.

Takata, H., Zheng, J., Tagami, K., Aono, T., Uchida, S., 2011. Determination of ${ }^{232}$ Th in seawater by ICP-MS after preconcentration and separation using a chelating resin. Talanta $85,1772-1777$.

Turner, A., Lewis, M.S., Shams, L., Brown, M.T., 2007. Uptake of platinum group elements by the marine macroalga, Ulva lactuca. Mar. Chem. 105, 271-280.

Turner, A., Pedroso, S.S., Brown, M.T., 2008. Influence of salinity and humic substances on the uptake of trace metals by the marine macroalga, Ulva lactuca: experimental observations and modelling using WHAM. Mar. Chem. 110, $176-184$.

Van den Berg C.M.G. Jacinto, G.S., 1988. The determination of platinum in seawater by adsorptive cathodic stripping voltammetry. Anal. Chim. Acta 211, 129-139.

Wang, J., Zhu, R.H., Shi, Y.Z., 2007. Distribution of platinum group elements in road dust in the Beijing metropolitan area. J. Environ. Sci. (China) 19, 29-34.

Wiseman, C.L.S., Zereini, F., 2009. Airborne particulate matter, platinum group elements and human health: a review of recent evidence. Sci. Total Environ. 407, 2493-2500.

Wood, S.A., 1991. Experimental determination of the hydrolysis constants of $\mathrm{Pt}^{2+}$ and $\mathrm{Pd}^{2+}$ at $25^{\circ} \mathrm{C}$ from the solubility of Pt and Pd in aqueous hydroxide solutions. Geochem. Cosmochim. Acta 55, 1759-1767. 